\title{
Evolutionary dynamics of the karyotype of the wasp Trypoxylon (Trypargilum) nitidum (Hymenoptera, Sphecidae) from the Rio Doce State Park, Minas Gerais, Brazil
}

\author{
Ricardo Scher ${ }^{1}$ and Silvia das Graças Pompolo ${ }^{2}$ \\ ${ }^{1}$ Universidade Federal de Sergipe, Departamento de Morfologia, São Cristóvão, SE, Brazil. \\ ${ }^{2}$ Universidade Federal de Viçosa, Departamento de Biologia Geral, Viçosa, MG, Brazil.
}

\begin{abstract}
Cytogenetic analysis based on the distribution of C-bands showed two groups of karyotypes in a Trypoxylon nitidum population from the Rio Doce Park, State of Minas Gerais, Brazil. One of these groups, that was identical to a previously described karyotype $(n=15 ; 2 n=30)$, had a stable chromosome number and was rich in acrocentric chromosomes, whereas the other had a variable chromosome number $(n=12$ to $14 ; 2 n=25$ to 28$)$ and was rich in pseudo-acrocentric chromosomes. We propose a hypothesis explaining the dynamics of the modifications which occurred in the karyotype of this species, based on the minimum interaction theory of Imai et al. $(1986,1988,1994)$ and on the chromosome rearrangements and heteromorphisms observed by us.
\end{abstract}

Key words: C-banding, Trypoxylon nitidum, karyotype evolution.

Received: May 19, 1999; Accepted: June 27, 2003.

\section{Introduction}

The occurrence of interspecific and intraspecific karyotypic variation is common in ants, especially in the Myrmecia (pilosula) species complex described by Imai et al. (1994), which is highly heterogeneous at the chromosome level $(2 \mathrm{n}=2-32)$ and comprises at least five karyotypically separate species, some of them presenting individuals with highly distinct karyotypes.

The diploid chromosome number of the species of genus Trypoxylon described by Hoshiba and Imai (1993), Gomes (1995), and Gomes et al. (1995, 1997) varies, at the interspecific level, from 18 to 34 . The karyotype variation includes Robertsonian rearrangements (centric fission and fusion), inversions, translocations, functional centromere change and increase in the amount of heterochromatin. Intraspecific variation in the genus has been reported by Gomes (1995) and by Araújo et al. (2000) for T. albitarse, with individuals presenting karyotypes from $2 \mathrm{n}=32$ to $2 n=34$. This variation was attributed to the presence of $B$ chromosomes.

Trypoxylon (Trypargilum) nitidum is a Sphecidae of solitary habits, found only in the western region of the Southern Hemisphere, where it nests in preexisting cavities. Its karyotype was described by Gomes (1995). The Rio

Send correspondence to Ricardo Scher. Universidade Federal de Sergipe, Departamento de Morfologia, São Cristóvão, SE, Brazil. E-mail: scher@ufs.br.
Doce Park population investigated in this study presented not only the standard karyotype, but also a related karyotype divergent in chromosome number and morphology. The objectives of the present study were to investigate the chromosomal rearrangements involved in this variation and to determine the evolutionary dynamics of this karyotype.

\section{Material and Methods}

The specimens were captured with the aid of trapnests consisting of bamboo stem sections of various lengths and diameters. The traps were distributed within the area of the Rio Doce State Park, MG, (19 $30^{\prime}$ S, $\left.41^{\circ} 1^{\prime} \mathrm{W}\right)$ and periodically inspected for occupancy. A total of 34 individuals, which were in the pre-pupa phase, were cytogenetically analyzed, and at least one specimen per nest was maintained in an incubator $\left(28^{\circ} \mathrm{C}\right)$ until adult eclosion, in order to be identified by a taxonomist. Metaphase chromosomes were prepared from cerebral ganglions of pre-pupae, according to the method of Imai et al. (1988) with modifications, and C-bands were obtained by the technique of Sumner (1972), modified by Pompolo and Takahashi (1990).

We analyzed about 20 metaphases per individual, and photographed those of best quality. The chromosomes were arranged in three groups: group $A$ consisting mainly of metacentrics, group $B$ of pseudo-acrocentrics, and group $C$ of acrocentrics. Chromosome nomenclature was based on 
the heterochromatin distribution pattern, as proposed by Imai (1991).

\section{Results}

In our sample from the Rio Doce Park, we found 13 individuals with the $2 \mathrm{n}=30$ and $\mathrm{n}=15$ karyotype previously described by Gomes (1995) in a sample from Viçosa, MG (Table 1).

The karyotype of these individuals was composed of one pair of small group $A$ metacentric chromosomes, five group $B$ pairs of pseudo-acrocentrics, and nine group $C$ pairs of acrocentrics (Figure $1 \mathrm{a}$ and $\mathrm{b}$ ).

We also found individuals with karyotypes which were numerically and morphologically distinct from those described previously. On the average, two individuals per nest were cytogenetically analyzed, and neither the karyotype pattern of individuals from the same nest, nor that of individuals from different nests showed any consistence. As a rule, the karyotypes of these individuals consisted of 3 group $A$ pairs of metacentrics $\left(\mathrm{M}^{\mathrm{CC}}\right.$ and $\left.\mathrm{M}^{\mathrm{C}}\right), 8$ group $B$ pairs of pseudo-acrocentrics $\left(\mathrm{A}^{\mathrm{M}}\right)$, and one group $C$ pair of acrocentrics (A). However, among the investigated females, 13 variant karyotypes were found, with a chromosome number ranging from $2 n=25$ to $2 n=28$. This variation was due to heteromorphisms observed in the three group $A$ pairs, and to the presence of one or two almost fully heterochromatic and unpaired pseudo-acrocentric chromosomes (Figure 2a). Differences were also observed in the heterochromatic arm of chromosome pairs $5 B, 6 B$, and $7 B$ (Figure 2a).
Table 1 - Chromosomal complement, karyotypic formula, nest number, and number of Trypoxylon (Trypargilum) nitidum specimens studied.

\begin{tabular}{|c|c|c|c|c|}
\hline \multicolumn{3}{|c|}{ Karyotype } & \multirow{2}{*}{$\begin{array}{c}\text { Nest } \\
\text { number }\end{array}$} & \multirow{2}{*}{$\begin{array}{c}\text { Number of } \\
\text { specimens } \\
\text { analyzed }\end{array}$} \\
\hline $2 n$ & (n) & Formula & & \\
\hline 30 & & $2 \mathrm{M}^{\mathrm{CC}}+10 \mathrm{~A}^{\mathrm{M}} 18 \mathrm{~A}$ & $\begin{array}{c}* 1,3,4 \\
6,8\end{array}$ & 6 \\
\hline \multirow[t]{3}{*}{28} & & $4 \mathrm{M}^{\mathrm{CC}}+18 \mathrm{~A}^{\mathrm{M}}+6 \mathrm{~A}$ & 10 & 1 \\
\hline & & $2 \mathrm{M}^{\mathrm{CC}}+2 \mathrm{M}^{\mathrm{C}}+18 \mathrm{~A}^{\mathrm{M}}+6 \mathrm{~A}$ & 11 & 1 \\
\hline & & $2 \mathrm{M}^{\mathrm{CC}}+2 \mathrm{M}^{\mathrm{C}}+18 \mathrm{~A}^{\mathrm{M}}+6 \mathrm{~A}$ & 12 & 1 \\
\hline \multirow[t]{7}{*}{27} & & $4 \mathrm{M}^{\mathrm{CC}}+1 \mathrm{M}^{\mathrm{C}}+17 \mathrm{~A}^{\mathrm{M}}+5 \mathrm{~A}$ & 10 & 1 \\
\hline & & $3 \mathrm{M}^{\mathrm{CC}}+2 \mathrm{M}^{\mathrm{C}}+16 \mathrm{~A}^{\mathrm{M}}+6 \mathrm{~A}$ & 11 & 1 \\
\hline & & $3 \mathrm{M}^{\mathrm{CC}}+2 \mathrm{M}^{\mathrm{C}}+17 \mathrm{~A}^{\mathrm{M}}+5 \mathrm{~A}$ & 11 & 1 \\
\hline & & $3 \mathrm{M}^{\mathrm{CC}}+2 \mathrm{M}^{\mathrm{C}}+16 \mathrm{~A}^{\mathrm{M}}+6 \mathrm{~A}$ & 12 & 1 \\
\hline & & $3 \mathrm{M}^{\mathrm{CC}}+2 \mathrm{M}^{\mathrm{C}}+16 \mathrm{~A}^{\mathrm{M}}+6 \mathrm{~A}$ & 12 & 1 \\
\hline & & $4 \mathrm{M}^{\mathrm{CC}}+1 \mathrm{M}^{\mathrm{C}}+17 \mathrm{~A}^{\mathrm{M}}+5 \mathrm{~A}$ & 13 & 1 \\
\hline & & $4 \mathrm{M}^{\mathrm{CC}}+1 \mathrm{M}^{\mathrm{C}}+16 \mathrm{~A}^{\mathrm{M}}+6 \mathrm{~A}$ & 14 & 1 \\
\hline 26 & & $4 \mathrm{M}^{\mathrm{CC}}+1 \mathrm{M}^{\mathrm{C}}+16 \mathrm{~A}^{\mathrm{M}}+5 \mathrm{~A}$ & 10 & 1 \\
\hline \multirow[t]{9}{*}{25} & & $4 \mathrm{M}^{\mathrm{CC}}+2 \mathrm{M}^{\mathrm{C}}+16 \mathrm{~A}^{\mathrm{M}}+2 \mathrm{~A}$ & 16 & 2 \\
\hline & & $6 \mathrm{M}^{\mathrm{CC}}+1 \mathrm{M}^{\mathrm{C}}+13 \mathrm{~A}^{\mathrm{M}}+5 \mathrm{~A}$ & 17 & 1 \\
\hline & 15 & $1 \mathrm{M}^{\mathrm{CC}}+5 \mathrm{~A}^{\mathrm{M}}+9 \mathrm{~A}$ & $\begin{array}{c}* 1,2,4,5 \\
7,8,9\end{array}$ & 7 \\
\hline & 14 & $2 \mathrm{M}^{\mathrm{CC}}+8 \mathrm{~A}^{\mathrm{M}}+4 \mathrm{~A}$ & 14 & 1 \\
\hline & 13 & $2 \mathrm{M}^{\mathrm{CC}}+1 \mathrm{M}^{\mathrm{C}}+8 \mathrm{~A}^{\mathrm{M}}+2 \mathrm{~A}$ & 13 & 1 \\
\hline & & $2 \mathrm{M}^{\mathrm{CC}}+1 \mathrm{M}^{\mathrm{C}}+8 \mathrm{~A}^{\mathrm{M}}+2 \mathrm{~A}$ & 15 & 2 \\
\hline & 12 & $2 \mathrm{M}^{\mathrm{CC}}+1 \mathrm{M}^{\mathrm{C}}+7 \mathrm{~A}^{\mathrm{M}}+2 \mathrm{~A}$ & 15 & 1 \\
\hline & & $3 \mathrm{M}^{\mathrm{CC}}+1 \mathrm{M}^{\mathrm{C}}+7 \mathrm{~A}^{\mathrm{M}}+1 \mathrm{~A}$ & 17 & 1 \\
\hline & & $2 \mathrm{M}^{\mathrm{CC}}+1 \mathrm{M}^{\mathrm{C}}+9 \mathrm{~A}^{\mathrm{M}}$ & 18 & 1 \\
\hline
\end{tabular}

*Karyotype as described by Gomes (1995).

a)



b)

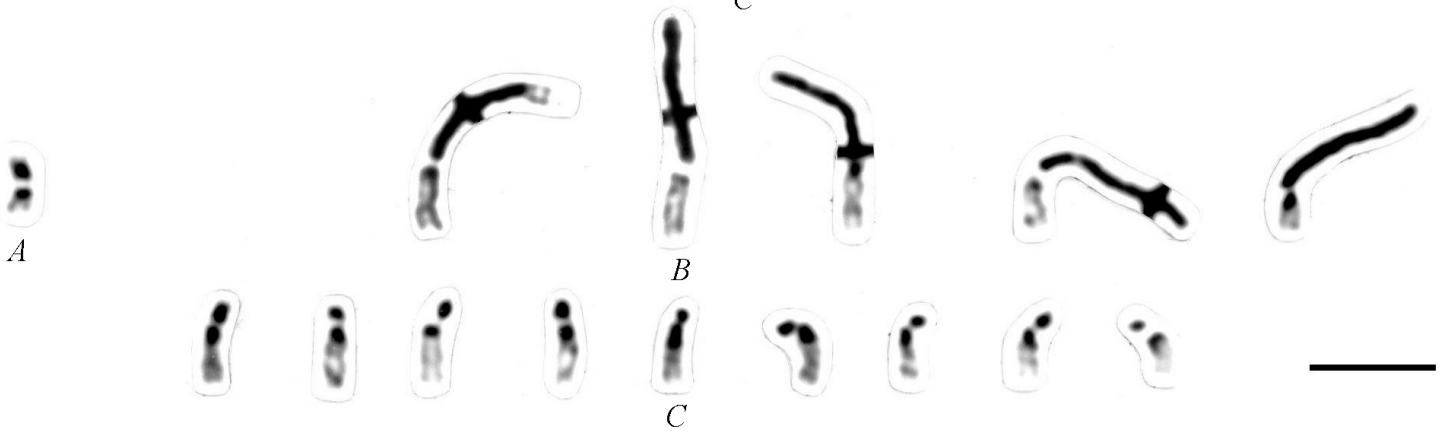

Figure 1 - a) Standard karyotype of a Trypoxylon nitidum female $(2 \mathrm{n}=30)$, after standard staining. b) Standard karyotype of a T. nitidum male ( $\mathrm{n}=15)$ after C-banding. Bar $=5 \mu \mathrm{m}$. 
a)

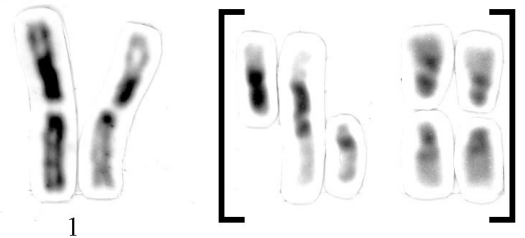

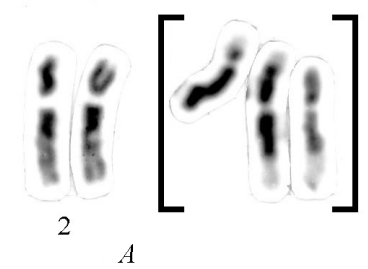

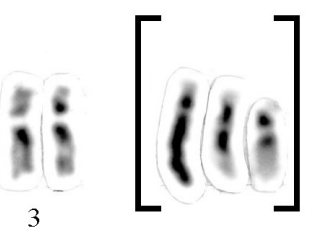

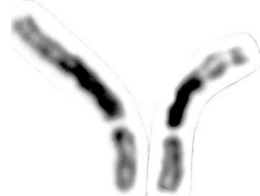

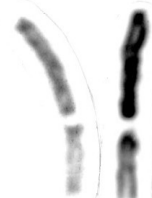

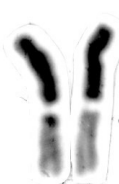

3

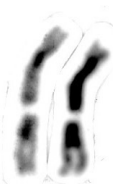

4

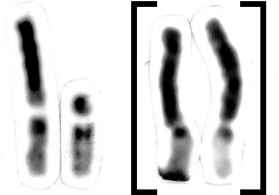

5

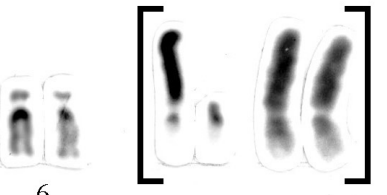

6

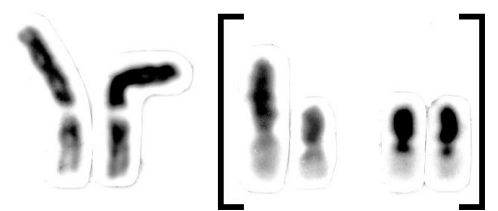

7

b)


1

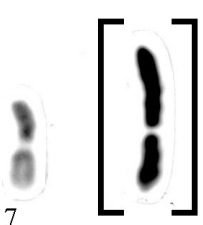



2

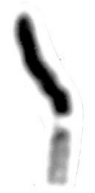

3

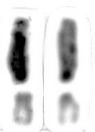

8

$B$

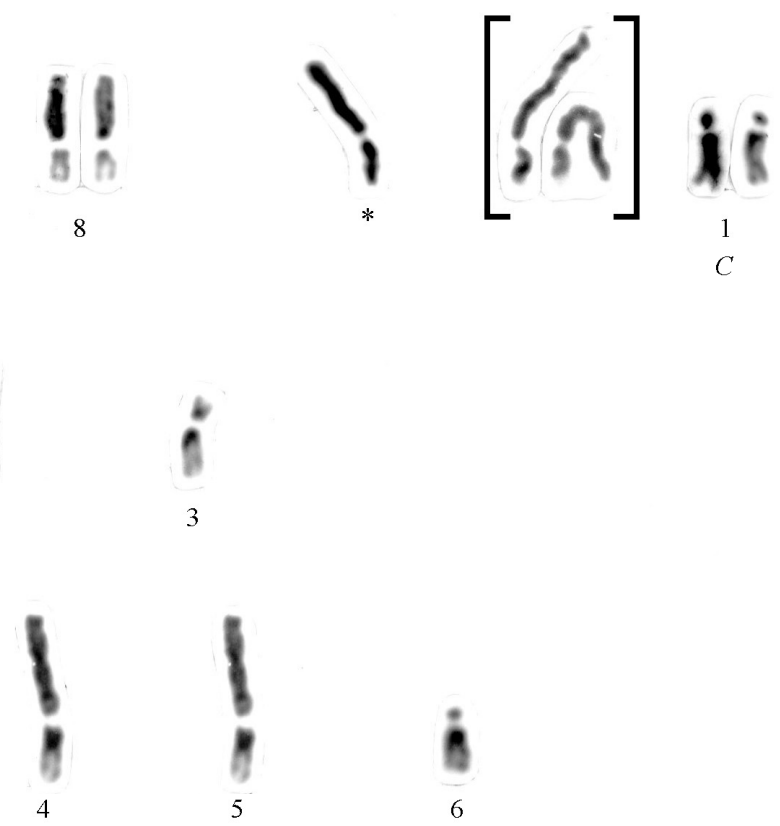

B

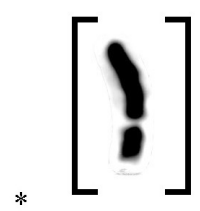

$B$

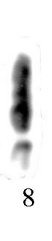

Figure 2 - a) Karyotype of a Trypoxylon nitidum female after C-banding. In the brackets are the C-banded heteromorphic pairs which generated the variation from $2 \mathrm{n}=25$ to $2 \mathrm{n}=28$. b) Karyotype of a T. nitidum male $(\mathrm{n}=12)$ after C-banding. In the brackets are the C-banded heteromorphic pairs which generated the variation from $n=12$ to $n=14{ }^{*}=B$ chromosomes. $\mathrm{Bar}=5 \mu \mathrm{m}$.

In males, there were six different karyotypes, ranging from $\mathrm{n}=12$ to $\mathrm{n}=14$ (Table 1), due to a heteromorphism of chromosome $1 \mathrm{~A}$, associated with the presence or absence of an almost fully heterochromatic pseudo-acrocentric chromosome. In these individuals, only chromosome $7 B$ presented size fluctuations of the heterochromatic arm (Figure 2b).

\section{Discussion}

Despite the clear cytogenetic differences described here, individuals with the karyotype illustrated in Figure 2 were morphologically identical to those with the previously described T. nitidum karyotype (Figure 1).

Considering all the specimens studied as being representative of $T$. nitidum, and comparing the two karyotypic groups, we note a sharp decrease in the number of group $C$ acrocentric chromosomes, along with an increase in the number of pseudo-acrocentric group $B$ chromosomes. Pseudo-acrocentric chromosomes were described by Imai et al. (1988) as acrocentrics with relatively long heterochromatic arms, which were formed by a rapid increase in 
heterochromatin. These researchers considered the extreme growth of the short heterochromatic arms of acrocentric chromosomes as a 'struggle' to recover a stable telomere replication system from a bare residual centromere generated by centric fission. This kind of rearrangement is frequent in Hymenoptera, especially in species with a high chromosome number, such as Myrmecia brevinoda that represents an extreme case with its 84 pseudo-acrocentric chromosomes (according to Imai et al. $(1977,1988)$. Thus, starting from the assumption that the standard T. nitidum karyotype $(2 \mathrm{n}=30)$ was established in the past by successive centric fissions, the recent increase in the number of pseudo-acrocentric chromosomes may be explained by a rapid increase in the heterochromatin of acrocentric chromosomes.

It seems unlikely that such a process would occur without any selective pressure, since the longer the arms the higher the risk of reciprocal translocation. It thus appears that some heterochromatin elimination mechanism has been adopted by the cell, possibly a series of translocations between pseudo-acrocentric chromosomes (or between pseudo-acrocentric and acrocentric chromosomes), eventually resulting in the formation of metacentric group $A$ pairs. This hypothesis is mainly based on the heteromorphism of pairs $2 A$ and $3 A$, with apparent homologies observed between certain regions of metacentric, acrocentric and pseudo-acrocentric chromosomes (Figure 2a), and also on the presence of apparently dicentric chromosomes (Figure $2 \mathrm{a}$, pair $2 A$ ), which are characteristic of this type of rearrangement (Imai et al., 1994). Although important in the process of heterochromatin elimination from the pseudoacrocentric chromosomes, this type of rearrangement is considered rare in the evolution of animal karyotypes (White, 1973). It was nevertheless observed by Imai et al. (1994) in ant species of the Myrmecia pilosula complex, and was also identified in wasps of the genus Vespula by Hoshiba et al. (1989) as one of the events in metacentric chromosome formation, by which pair $1 \mathrm{~A}$ also seems to have been formed. However, in order to achieve greater karyotype stability, this pair of chromosomes may still be undergoing fission, as demonstrated by the one-armed heteromorphism pattern that, according to Imai et al. (1994), is characteristic of this kind of rearrangement.

The almost fully heterochromatic and unpaired pseudo-acrocentric chromosomes shown in Figure 2 may represent free heterochromatin blocks resulting from the translocations described above. Based on evidence showing that the heterochromatic blocks formed by a heterochromatin increase may involve multiple centromeres and usually inactive telomeres (Imai, 1991), it can be assumed that these blocks have acquired mitotic stability as a result of reactivation of these sequences, starting from appropriate structural rearrangements, and may therefore be considered as extra chromosomes.
Thus, we suggest that a series of fissions occurred in the past in a metacentric ancestral karyotype with a low chromosome number may have initiated the acrocentricrich form $2 \mathrm{n}=30$. A sudden heterochromatin increase in these chromosomes may have generated the high instability presented by the pseudo-acrocentric karyotype, leading to translocation and formation of a metacentric karyotype. After elimination of excess chromatin, a new fission cycle may have started, a process which, based on the inferred dynamics of pair $1 A$, we suggest may still be occurring in this population.

The diploid number of euchromatic arms $(2 \mathrm{AN}=30)$, identical in all the wasps analyzed, may explain the occurrence and viability of individual wasps bearing multiple rearrangements which seem to involve only elimination of heterochromatic regions. According to the minimum interaction theory (Imai et al., 1986, 1988, 1994), whatever the effect on chromosome morphology or number, these changes may play the role of minimizing nonspecific chromosome interactions during interphase.

Although the fate of the population we studied is uncertain, at least two paths may be inferred from the chromosomal changes observed: one, that chromosomal rearrangements will generate a reproductive barrier between the two karyotype groups, giving rise to a new taxon; the other one, leading to the reestablishment of the standard karyotype by centric fissions, after heterochromatin elimination.

The hypothesis that there are two reproductively isolated groups is supported by the fact that variant karyotypes do not present the high number of acrocentric chromosomes observed in group $C$ of the standard karyotype, suggesting that no hybridization between the $2 \mathrm{n}=30$ karyotypes and the others seems to be occurring. On the other hand, the high number of variants observed within the same nest and among different nests suggests that wasps with different karyotypes are mating with each other. Therefore, if reproductive isolation is occurring, it appears to be incipient.

\section{Acknowledgments}

The authors would like to thank CNPq and CAPES for financial support, the Rio Doce State Park Administrator for giving us access to the material, and Dr. S.T.P. Amarante for identifying the specimens.

\section{References}

Araújo SMRS, Pompolo SG, Dergam JA and Campos LAO (2000) The B chromosome system of Trypoxylon (Trypargilum) albitarse (Hymenoptera, Sphecidae). 1. Banding analysis. Cytobios 101:7-13.

Gomes LF (1995) Estudos citogenéticos em vespas do gênero Trypoxylon (Hymenoptera, Sphecidae, Larrinae, Trypoxylonini). Master's Thesis, Universidade Federal de Viçosa, Viçosa, MG, Brasil. 
Gomes LF, Pompolo SG and Campos LAO (1995) Cytogenetic analysis of three species of Trypoxylon (Trypoxylon) (Hymenoptera, Sphecidae, Larrinae). Rev Bras Genet 18:173-176.

Gomes LF, Pompolo SG and Campos LAO (1997) Karyotype evolution in wasps of the genus Trypoxylon (subgenus Trypargilum) (Hymenoptera, Sphecidae). Brazil Jour Genet 20:177-183.

Hoshiba H and Imai HT (1993) Chromosome evolution of bees and wasps (Hymenoptera, Apocrita) on the basis of Cbanding pattern analyses. Jpn J Ent 61(3):465-492.

Hoshiba H, Matsuura M and Imai HT (1989) Karyotype evolution in the social wasps (Hymenoptera, Vespidae). Jpn J Genet 64:209-222.

Imai HT (1991) Mutability of constitutive heterochromatin (Cbands) during eukaryotic chromosomal evolution and their cytological meaning. Jpn J Genet 66:635-661.

Imai HT, Crozier RH and Taylor RW (1977) Karyotype evolution in Australian ants. Chromosoma 53:341-393.
Imai HT, Maruyama T, Gojobori YI and Crozier RS (1986) Theoretical bases for karyotype evolution. 1. The minimuminteraction hypothesis. Am Nat 128(6):900-920.

Imai HT, Taylor RW, Crosland MWJ and Crozier RH (1988) Modes of spontaneous chromosome mutation and karyotype evolution in ants with reference to the minimum interaction hypothesis. Jpn J Genet 63:113-125.

Imai HT, Taylor R W and Crozier RH (1994) Experimental bases for the minimum interaction theory: I Chromosome evolution in ants of Myrmecia pilosula species complex (Hymenoptera: Formicidae: Myrmeciinae). Jpn J Genet 69:137-181

Pompolo SG and Takahashi CS (1990) Chromosome numbers and $\mathrm{C}$ banding in two species of the genus Polistes (Hymenoptera, Polistinae, Polistinii). Insec Sociaux 37:251-217.

Sumner OW (1972) A simple technique for demonstrating centromeric heterochromatin. Exp Cell Res 75:304-306.

White MJD (1973) Animal cytology and evolution. 3rd edition. Cambridge University Press, London, 961 pp.

Editor: Yatiyo Yonenaga-Yassuda 